Pathophysiology Haemostasis and Thrombosis

\title{
Antithrombotics and Cancer: Evidence for Survival Benefit
}

\author{
Ajay K. Kakkar \\ Hammersmith Hospital - Imperial College, Thrombosis Research Institute, London, UK
}

It is well recognised that an early manifestation of malignant disease may be an underlying hypercoagulable state with the potential for clinical venous thromboembolic (VTE) disease. The recognition that a potentially fatal disease, such as VTE, can occur frequently in patients with cancer and that the proteases involved in blood coagulation activation have direct cellular effects, altering phenotypic behaviour of tumour cells, lends mechanistic credence to clinical observations and prospective clinical evaluations that indicate that both the oral anticoagulant warfarin and unfractionated heparin may alter clinical outcome in cancer patients.

The impact of VTE in the cancer patient is only now beginning to be fully recognised. Studies where VTE prophylaxis is used in surgical patients indicate that, although effective, fatal PE is at least three times as common in cancer as non-cancer patients receiving heparin or LMWH for prophylaxis. These data and large population based analyses indicate that cancer patients with thrombosis have an adverse outcome when compared to those patients without thrombosis; thus effective VTE prophylaxis may impact on survival in the cancer patient.

\begin{tabular}{ll}
\hline KARGER & (c) 2003 S. Karger AG, Basel \\
Fax +41 61 306 1234 & 1424-8832/03/0337-0067\$19.50/0 \\
$\begin{array}{l}\text { E-Mail karger@karger.ch } \\
\text { www.karger.com }\end{array}$ & $\begin{array}{l}\text { Accessible online at: } \\
\text { www.karger.com/journals/pht }\end{array}$
\end{tabular}

More recently, the first double blind, randomised, prospective, controlled trial (FAMOUS) has compared the LMWH dalteparin with placebo in patients with advanced cancer to determine any potential survival benefit of chronic LMWH administration. In the FAMOUS trial, 385 patients randomised to receive either dalteparin or placebo were assessed for effects on 1 year mortality. A trend to improve survival was seen in the dalteparin group ( $46 \%$ vs $41 \%$ ); a subgroup of 102 patients with a better prognosis, surviving beyond 17 months, showed an increase in median survival from 24 to 43 months $(p=0.03)$. These data with dalteparin are further supported from a subgroup analysis of 677 cancer patients with acute DVT randomised to receive either 6 months or oral anticoagulant therapy or six months of dalteparin for secondary prevention of VTE in the CLOT study. In patients without metastatic disease $(\mathrm{n}=150)$ dalteparin administration was associated with a $15 \%$ survival advantage at 1 year $(35 \%$ vs $20 \%$; HR 0.50 , $95 \%$ CI $0.27-0.95, \mathrm{p}=0.03$ ).

Dr. Ajay K. Kakkar

Hammersmith Hospital - Imperial College

Thrombosis Research Institute, Emmanuel Kaye Building

SW3 6LR - London, England (UK)

Tel. +44 2073518309 , Fax +44 2073518317

E-Mail akkakkar@tri-london.ac.uk 
